\title{
EXPRESSION OF SURVIVIN AND p53 IN BREAST CANCER
}

\author{
Nath Dwijendra1 , Agrawal Pallavi², Singh Arun ${ }^{3}$, Rawat Niharika ${ }^{4}$ \\ 1 Professor and HOD, Department of Pathology, MLB Medical College, Jhansi. \\ ${ }^{2}$ Assistant Professor, Department of Pathology, MLB Medical College, Jhansi. \\ ${ }^{3}$ Resident, Department of Pathology, MLB Medical College, Jhansi. \\ ${ }^{4}$ Resident, Department of Pathology, MLB Medical College, Jhansi.
}

\section{ABSTRACT}

\section{BACKGROUND}

Survivin, a novel inhibitor of apoptosis, that inhibits caspases and blocks cell death, is highly expressed in most cancers. Many studies have indicated that aberrant expression of Survivin is associated with poor prognosis, drug and radiation resistance. The p53 gene is a tumor suppressor gene. The significance of p53 detection is that p53 mutation is linked with chemo resistance and transformation to more aggressive disease in a large number of tumor cell types.

Aim- To study the expression of Survivin and mutant p53 in breast cancer and its effect on clinical outcome in breast cancer patients.

\section{MATERIALS AND METHODS}

It is a descriptive study on 75 patients. Paraffin embedded tissue samples from 34 untreated female patients with Invasive ductal carcinoma and 41 female patients with fibroadenoma were used. Expression of Survivin and mutant p53 was evaluated using immunohistochemistry staining method.

\section{RESULTS}

In our study, 79.4\% cases of invasive ductal carcinomas and 37.5\% cases of fibroadenoma stained positive of survivin. While $85 \%$ cases of invasive ductal carcinomas and $50 \%$ cases of fibroadenoma stained positive for $\mathrm{p} 53$.

\section{CONCLUSION}

Increased expression of Survivin and mutant p53 in IDC patients suggest that Survivin and p53 are likely to contribute significantly to apoptosis resistance and may serve as therapeutic target that could increase the effectiveness of conventional breast cancer therapy.

\section{KEYWORDS}

Survivin, p53, Breast Cancer, Invasive Ductal Carcinoma, Fibroadenoma.

HOW TO CITE THIS ARTICLE: Dwijendra N, Pallavi A, Arun S, et al. Expression of survivin and P53 in breast cancer. J. Evolution Med. Dent. Sci. 2018;7(07):881-885, DOI: 10.14260/jemds/2018/201

\section{BACKGROUND}

Breast cancer is by far the leading cause of cancer death in women throughout the world and its incidence continues to rise .(1,2) Metastasis occurs at an early stage and so does the resistance to wide range of anticancer drugs.(3) Survivin is a multifactorial protein implicated in control of cell proliferation,(4) inhibition of apoptosis(5) and the promotion of angiogenesis.(6-8) Survivin is undergoing intensive investigations as a potential tumor marker because of the large difference in expression between normal and malignant tissue. Its causal role in cancer progression and its possible involvement in tumor cell resistance to radiation and chemotherapeutic drugs, $(9,10)$ is being studied. Its expression is highly cell cycle regulated, and is detectable in the nucleus selectively at the G2/M phase.(4) However, the correlation of nuclear expression with the aggressiveness of tumour has not been conclusive. Furthermore, when treated with chemotherapeutic drugs, cultured breast cancer cells were

'Financial or Other Competing Interest': None.

Submission 21-11-2017, Peer Review 31-01-2018,

Acceptance 05-02-2018, Published 12-02-2018.

Corresponding Author:

Dr. Agrawal Pallavi,

Department of Pathology,

MLB Medical College, Jhansi.

E-mail: pallavinutan2010@gmail.com

DOI: $10.14260 /$ jemds $/ 2018 / 201$ found to increase the expression of survivin, in an attempt to resist apoptosis.(11-13) Transcription of survivin has been shown to be directly repressed by wild-type p53, another cell cycle checkpoint-regulating protein that induces apoptosis.(14) On the contrary, ErbB2 regulate survivin protein expression in ErbB2 overexpressing breast cancer cell and survivin expression is suppressed when ErbB2 was selectively knocked down(15) and this results in apoptosis of ErbB2 overexpressing breast cancer cells. Moreover, one of the most significant features of survivin is its differential distribution in cancer compared to normal tissue. Overexpression of survivin has been demonstrated in tumours of the lung, breast,(16) oesophagus, pancreas, bladder, uterus, cervix, ovary,(17-19) large-cell non-Hodgkin's lymphoma and leukaemia,(20-23) neuroblastomas, melanomas, gastric tumours,(24-26) colon cancer,(27-28) stomach and liver cancers,(11) oral cancers,(29-31) thyroid tumours,(31) laryngeal squamous cell carcinoma,(32) osteosarcoma,(33) and prostatic cancer.(34) Despite its role in mitosis, it is clear that overexpression of survivin in cancer does not simply reflect the presence of a higher number of proliferating cells.

The p53 gene is located on the seventeenth chromosome (17p13.1), also known as TP53- "Tumor Protein 53", which regulates the cell cycle and hence functions as a tumor suppressor protein. Defective p53 allows abnormal cells to proliferate resulting in cancer. $50 \%$ of all tumours contain p53 mutants. If p53 is damaged, tumor suppression is 
severely reduced.[35] Over expression of the nuclear phosphoprotein p53 is one of the most common abnormalities in primary human cancer and appears to be due to point mutation within a highly conserved region of the p53 gene which then encodes for a mutant, more stable protein.[36] Some experiments indicated that p53 inhibits expression of an inhibitory apoptosis protein survivin. Mutation in p53 leads to over expression of survivin which inhibits apoptosis and leads to tumours.[37] The current study was designed to investigate expression of Survivin and mutant p53 protein in paraffin sections of benign breast disease (Fibroadenoma) patients and invasive ductal carcinoma patients.

\section{MATERIALS AND METHODS}

This descriptive study was carried out in Dept. of Pathology, M.L.B. Medical College, Jhansi. The tissue material was obtained from patients admitted in Dept. of Surgery for breast conservation surgery/ modified radical mastectomy and lumpectomy. Histopathologically proven cases of invasive ductal carcinoma and fibroadenoma were selected after being fixed in $10 \%$ buffered formalin and embedded in paraffin for immunohistochemical analysis. Specimen consisted of 34 cases of invasive ductal carcinoma (ages 25 to 50 years) and 41 cases of fibroadenoma (ages 20 to 50 years). Cases other than IDC and fibroadenoma were not included.

\section{Immunohistochemical Analysis}

Serial 2-3 $\mu$ thick sections were made and mounted on polyL-lysine coated slides. Paraffin sections were immersed in xylene for $5 \mathrm{~min}$ and hydrated using a gradient series of alcohol. Antigen retrieval was performed by immersing the sections in citric acid buffer ( $\mathrm{pH}$ 6.0), in a microwave oven for 15 min. Endogenous peroxidase activity was blocked with $3 \%$ hydrogen peroxide for $10 \mathrm{~min}$ and then incubated with a primary antibody in a humidified chamber at $4^{0} \mathrm{C}$ overnight. Biogenex monoclonal rabbit antibodies to Survivin and biogenex monoclonal mouse antibodies to p53 were used. The correlation between the level of expression and the histological grade was analysed using the fisher exact test.

\section{Interpretation of Slides}

The scoring method for the expression of Survivin and p53 was a modified version of the system used by Tanaka et al. The mean percentage of positive cells was determined in at least five areas at 400-fold magnification and assigned one of the following five categories.

- $0:<5 \%$

- $1: 5-25 \%$

- $2: 25-50 \%$

- $3: 50-75 \%$

- $4:>75 \%$

The Intensity of Immunostaining was categorized as follows

1. Weak.

2. Moderate.

3. Intense.

Because of heterogenicity of immunostaining, the dominant pattern was used for scoring.

\section{Statistical Analysis}

Statistical analysis was performed using GraphPad Instat 3 software. Fisher exact test was used to find out the significant difference in expression of Survivin and p53 in benign and malignant tissues.

\section{RESULTS}

Survivin expression was observed in 15 out of 41 (37.5\%) cases of benign breast disease. Survivin was mainly immunolocalised in cytoplasm. The immunohistochemical analysis of invasive ductal carcinoma of breast showed Survivin expression in 27 out of 34 (79.4\%) cases. Overall, statistically significant increase in the level of Survivin expression was observed in IDC as compared to benign cases $(\mathrm{P}=0.0035$, Fisher exact test $)$
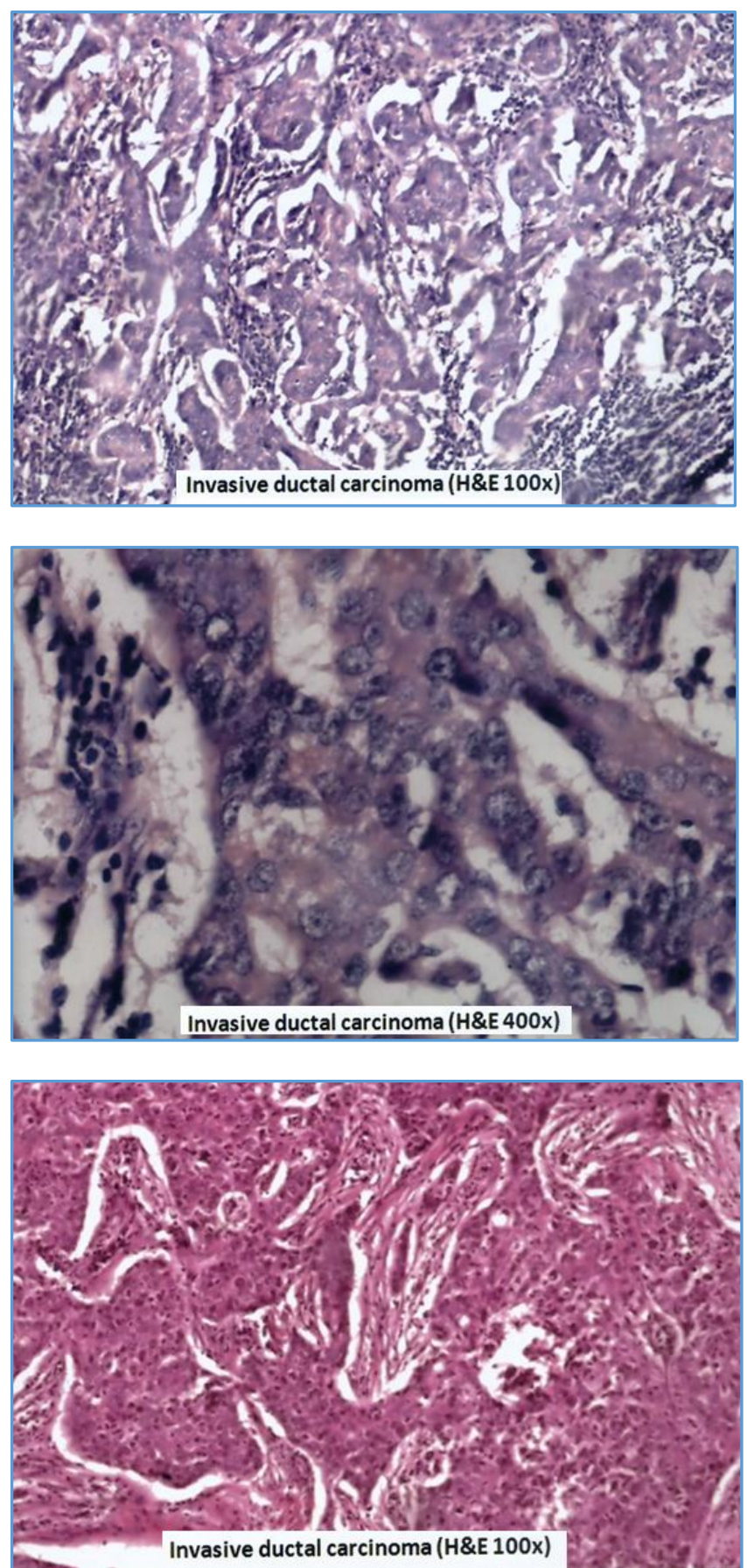

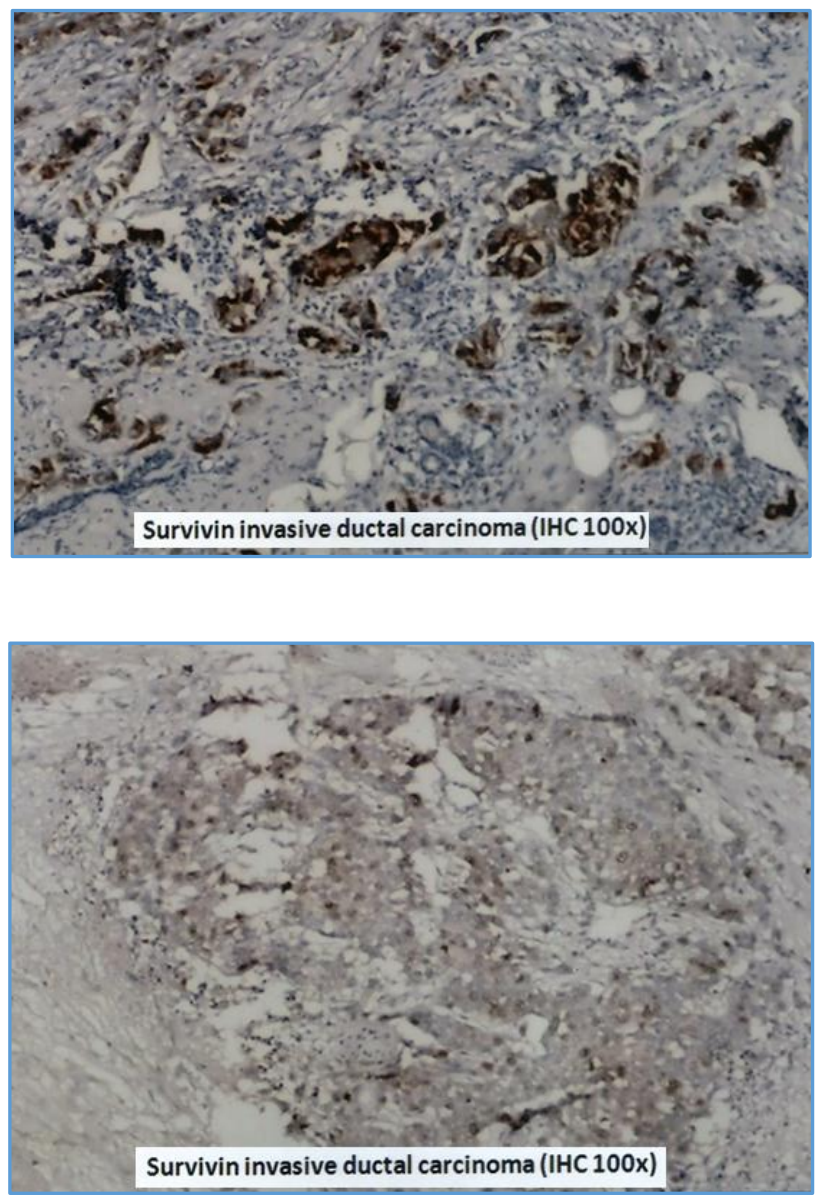

In immunohistochemical analysis of p53 protein, it was observed that only $50 \%$ (20 out of 41 ) of fibroadenoma cases expressed p53 protein while 29 out of 34 (85\%) of IDC cases expressed p53. Thus, statistically significant increase in mutant p53 was seen in carcinoma cases as compared to benign breast cases $(\mathrm{P}=0.003$, Fisher exact test $)$.

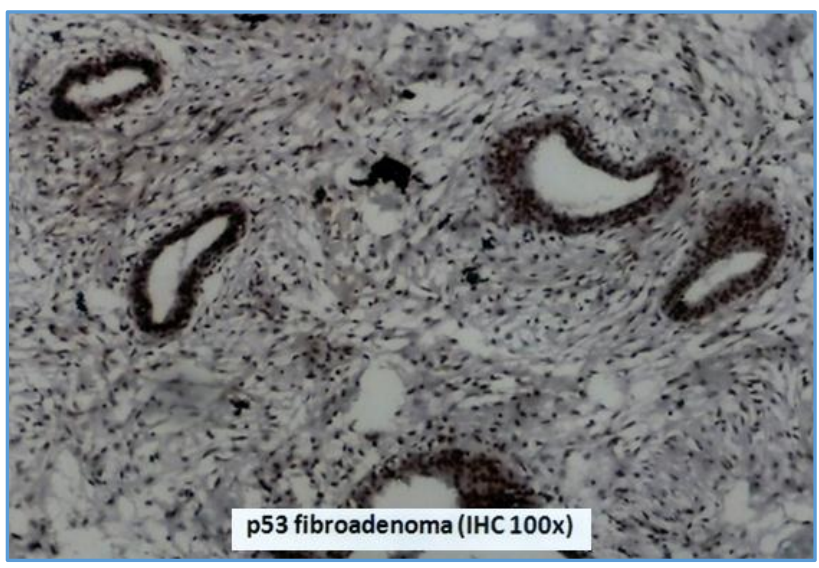

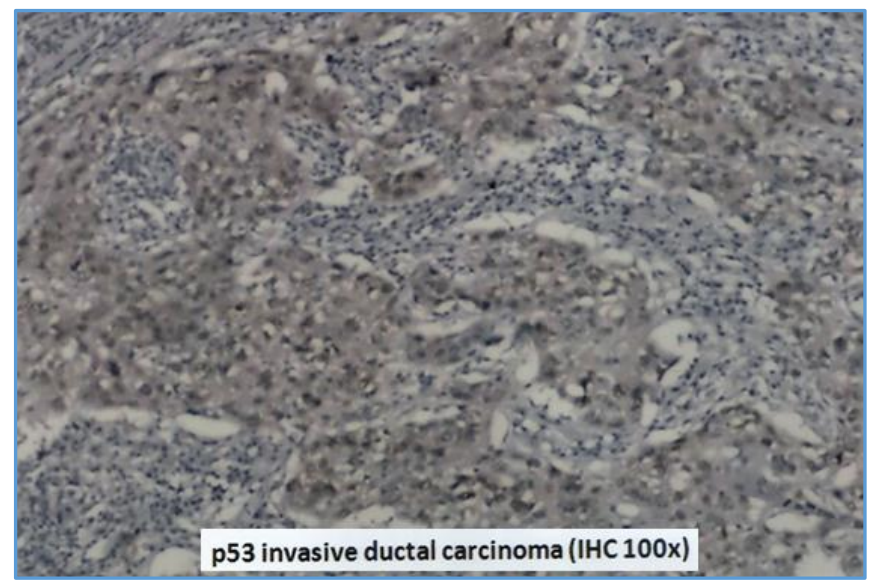

\section{DISCUSSION}

It is reported that the occurrence and development of tumours is controlled not only by the oncogenes activation or tumor suppressor genes inactivation, but also by apoptosis regulation. In this study, we found the expression of Survivin and mutant p53 in benign breast disease (fibroadenoma) and in invasive ductal carcinoma by immunohistochemical staining. Survivin is characterized by a unique structure with a single BIR and no zinc-binding domain known as RING finger, and by a selective distribution in common human cancers but not in normal adjacent tissues in vivo.(5) In the present study, statistically significant difference in the expression of survivin between benign breast disease (37.5\%) and breast carcinoma (79.4\%) $(\mathrm{P}=0.0035$, Fischer exact test) was observed. Our result is consistent with the observation of Nassar et al., who had reported $81 \%$ Survivin positivity in breast cancer cases, (38) whereas according to Zhang et al., Survivin was expressed in $42.7 \%$ of benign breast tumours. Normally Survivin is undetectable in terminally differentiated adult tissues, therefore, Survivin expression in benign cases is likely to be the result of dysplastic transformation of breast epithelium. Nevertheless, high survivin expression has been reported to correlate with poor prognosis(39) and has been used as an indicator to predict poor response to endocrine therapy, but a good response to chemotherapy in advanced breast cancer.(40) Similar findings have been reported in bladder mucosa, transitional cell carcinoma ${ }^{(41)}$ and in gastric cancer.(42) Using monoclonal and polyclonal antibodies, different subcellular pools of survivin have been detected. A nuclear pool that segregates with nucleoplasmic proteins was identified, and a separate, and predominantly cytosolic pool, was associated with interphase microtubules, centrosomes, spindle poles, and mitotic spindle microtubules at the metaphase and anaphase. These two types of survivin are immunochemically distinct, independently modulated during cell cycle progression, and only cytosolic survivin associates with p34cdc2. Phosphorylation of survivin byp34cdc2 - cyclin B has been identified as a requisite for apoptosis inhibition. $(43,44)$ 
The postulated explanation for these findings was that separate post-translational modifications could differently affect epitope accessibility of nuclear versus cytosolic microtubule-bound survivin in vivo. Hence, when nuclear survivin cannot associate with p34, an essential step in apoptosis, apoptosis may eventually be induced. This may explain why different patterns of survivin localization are seen in different tumour types and associated with different prognoses. Moreover, it was reported that survivin-3B may act as an anti-apoptotic factor in breast cancer, where the expression of the variants of survivin varies differentially with tumour progression and treatment. (45)

Disruption of p53 gene function seems to have a pivotal role in carcinogenesis. It has been demonstrated by Rohan et al.(46) that p53 gene changes occur before the development of breast cancer and therefore influence breast cancer risk. P53 has also been reported to regulate Survivin expression. In our study, $50 \%$ (20 out of 41 ) of benign cases showed nuclear p53 expression. Sirotkovic et al(47) demonstrated $19 \%$ of benign cases with nuclear p53 expression. The follow-up study in these 4 benign patients showed no development of breast cancer for at least 4 to 5 years. These findings are contradictory to the findings by Rohan et al., who concluded that p53 immunopositivity detected in normal or benign tissue is associated with increased risk of subsequent breast cancer. But to draw any conclusion, follow-up study of a large number of cases needs to be carried out. Statistically significant $(\mathrm{P}=0.003$, Fischer exact test) increase in mutant p53 expression was observed in IDC cases as compared to benign cases. P53 expression was seen in $85.30 \%$ (29 out of 34) cases.

\section{CONCLUSION}

From our study, we state that increased expression of Survivin and mutant p53 in IDC patients compared to benign cases is likely to contribute significantly to apoptosis resistance. Though Survivin is likely to contribute to apoptosis resistance, its role in predicting prognosis is still unclear and a study with larger sample size is required.

\section{REFERENCES}

[1] Tsai WC, Chu CH, Yu CP, et al. Matriptase and survivin expression associated with tumor progression and malignant potential in breast cancer of Chinese women: tissue microarray analysis of immunostaining scores with clinicopathological parameters. Dis Markers 2008;24(2):89-99.

[2] Sant M, Francisci S, Capocaccia R, et al. Time trends of breast cancer survival in Europe in relation to incidence and mortality. Int J Cancer 2006;119(10):2417-22.

[3] Gonzalez-Angulo AM, Morales-Vasquez F, Hortobagyi GN. Overview of resistance to systemic therapy in patients with breast cancer. Adv Exp Med Biol 2007;608:1-22.

[4] Reed JC, Bischoff JR. BIRinging chromosomes through cell division-and survivin' the experience. Cell 2000;102(5):545-8.

[5] Ambrosini G, Adida C, Altieri DC. A novel antiapoptosis gene, survivin, expressed in cancer and lymphoma. Nat Med 1997;3(8):917-21.
[6] Tran J, Rak J, Sheehan C, et al. Marked induction of the IAP family anti-apoptotic proteins surviving and XIAP by VEGF in vascular endothelial cells. Biochem Biophys Res Commun 1999;264(3):781-8.

[7] Tran J, Master Z, Yu JL, et al. A role for survivin in chemoresistance of endothelial cells mediated by VEGF. Proc Natl Acad Sci U S A 2002;99(7):4349-54.

[8] Blanc-Bride OP, Mesri M, Wall NR, et al. Therapeutic targeting of the surviving pathway in cancer: initiation of mitochondrial apoptosis and suppression of tumorassociated angiogenesis. Clin Cancer Res 2003;9(7):2683-92.

[9] Zaffaroni N, Pennati M, Daidone MG. Survivin as a target for new anticancer interventions. J Cell Mol Med 2005;9(2):360-72.

[10] Duffy MJ, O'Donovan N, Brennan DJ, et al. Survivin: a promising tumor biomarker. Cancer Lett 2007;249(1):49-60.

[11] Kennedy SM, O’Driscoll L, Purcell R, et al. Prognostic importance of survivin in breast cancer. Br J Cancer 2003;88(7):1077-83.

[12] Tanaka K, Iwamoto S, Gon G, et al. Expression of survivin and its relationship to loss of apoptosis in breast carcinomas. Clin Cancer Res 2000;6(1):127-34.

[13] Al-Joudi FS, Iskandar ZA, Samsudin AR. The effects of chemotherapeutic drugs on viability, apoptosis and survivin expression in MCF-7 cells. Acta Histochem Cytochem 2005;38(5):323-30.

[14] Mirza A, McGuirk M, Hockenberry TN, et al. Human survivin is negatively regulated by wild-type p53 and participates in p53-dependent apoptotic pathway. Oncogene 2002;21(17):2613-22.

[15] Xia W, Bisi J, Strum J, et al. Regulation of survivin by ErbB2 signaling: therapeutic implications for ErbB2overexpressing breast cancers. Cancer Res 2006;66(3):1640-7.

[16] Zhang SQ, Qiang SY, Yang WB, et al. Expression of survivin in different stages of carcinogenesis and progression of breast cancer. $\mathrm{Ai}$ Zheng 2004;23(6):697-700.

[17] Wang M, Wang B, Wang X. A novel antiapoptosis gene, surviving and bcl-2, expression in cervical carcinomas. Chin Med J 2001;114:149-53.

[18] Tao J, Shulan Z, Bei L, et al. The role of surviving gene in the chemoresistance of ovarian cancer cell. Singapore J Obst Gynaecol 2004;35:40-7.

[19] Tarkowski R, Kotarski J, Polak G, et al. Expression of survivin gene in the scar endometriosis and in normal human endometrium. Ginekologia Polska 2001;72(12A):1539-42.

[20] Carter BZ, Millela M, Altieri DC, et al. Cytokineregulated expression of survivin in myeloid leukemia. Blood 2001;97(9):2784-90.

[21] Carter BZ, Wang RY, Schober WD, et al. Targeting survivin expression induces cell proliferation defect and subsequent cell death involving mitochondrial pathway in myeloid leukemic cells. Cell Cycle 2003;2(5):488-93.

[22] Mori A, Wada H, Nishimura Y, et al. Expression of the antiapoptosis gene survivin in human leukemia. Int J Hematol 2002;75(2):161-5. 
[23] Schlette EJ, Medeiros LJ, Goy A, et al. Survivin expression predicts poorer prognosis in anaplastic large-cell lymphoma. J Clin Oncol 2004;22(9):1682-8.

[24] Li YH, Wang C, Meng K, et al. Influence of surviving and caspase-3 on cell apoptosis and prognosis in gastric carcinoma. World J Gastroenterol 2004;10(13):19848.

[25] Lu CD, Altieri DC, Tanigawa N. Expression of a novel antiapoptosis gene, survivin, correlated with tumor cell apoptosis and p53 accumulation in gastric carcinomas. Cancer Res 1998;58(9):1808-12.

[26] Yu J, Leung WK, Ebert MP, et al. Increased expression of surviving in gastric cancer patients and in first degree relatives. Br J Cancer 2002;87(1):91-7.

[27] Sarela AI, Scott N, Ramsdale J, et al. Immunohistochemical detection of the anti-apoptosis protein, survivin, predicts survival after curative resection of stage II colorectal carcinomas. Ann Surg Oncol 2001;8(4):305-10.

[28] Yang D, Zhu YQ, Qi J. Expression and clinical significance of surviving gene and PTEN protein in colorectal adenocarcinoma. Ai Zheng 2004;23(3):3069.

[29] Lo Muzio L, Campisi G, Giovannelli L, et al. HPV DNA and survivin expression in epithelial oral carcinogenesis: a relationship? Oral Oncol 2004;40(7):736-41.

[30] Lo Muzio L, Pannone G, Staibano S, et al. Survivin expression in oral squamous cell carcinoma. $\mathrm{Br} \mathrm{J}$ Cancer 2003;89(12):2244-8.

[31] Sugawara M, Matsuzuka F, Fukata S, et al. Excessive surviving expression in thyroid lymphomas. Hum Pathol 2002;33(5):524-7.

[32] Dong Y, Sui L, Watanabe Y, et al. Survivin expression in laryngeal squamous cell carcinomas and its prognostic implications. Anticancer Res 2002;22(4):2377-83.

[33] Wang W, Luo H, Wang A. Expression of survivin and correlation with PCNA in osteosarcoma. J Surg Oncol 2006;93(7):578-84.

[34] Xia XY, Li LH, Li XC, et al. Expression and significance of surviving protein, PTEN in prostatic cancer. Zhonghua Nan Ke Xue 2006;12(4):346-8, 351.

[35] Abdullah S, Sameer SA, Dil-Afroze, et al. P53-The molecular guardian crashes in gastric adenocarcinomas - a study in an ethnic Kashmiri population. J Carcinogene Mutagene 2010;1:106.

[36] Davidoff AM, Kerns BJ, Iglehart JD, et al. Maintenance of p53 alterations throughout breast cancer progression. Cancer Res 1991;51(10):2605-10.
[37] Végran F, Boidot R, Oudin C, et al. Association of p53 gene alterations with the expression of antiapoptotic survivin splice variants in breast cancer. Oncogene 2007;26(2):290-7.

[38] Nassar A, Sexton D, Cotsonis G, et al. Survivin expression in breast carcinoma: correlation with apoptosis and prognosis. Appl lmmunohistochem Mol Morphol 2008;16(3):221-6.

[39] Ryan BM, Konecny GE, Kahlert S, et al. Survivin expression in breast cancer predicts clinical outcome and is associated with HER2, VEGF, urokinase plasminogen activator and PAI-1. Ann Oncol 2006;17(4):597-604.

[40] Span PN, Tjan-Heijnen VC, Manders P, et al. High survivin predicts a poor response to endocrine therapy, but a good response to chemotherapy in advanced breast cancer. Breast Cancer Res Treat 2006;98(2):223-30.

[41] Lehner R, Lucia MS, Jarboe EA, et al. Immunohistochemical localization of the IAP protein survivin in bladder mucosa and transitional cell carcinoma. Appl Immunohistochem Mol Morphol 2002;10(2):134-8.

[42] Okada E, Murai Y, Matsui K, et al. Survivin expression in tumor cell nuclei is predictive of a favorable prognosis in gastric cancer patients. Cancer Lett 2001;163(1):109-16.

[43] O'Connor DS, Schechner JS, Adida C, et al. Control of apoptosis during angiogenesis by survivin expression in endothelial cells. Am J Pathol 2000;156(2):393-8.

[44] Rodriguez JA, Span SW, Ferreira CG, et al. CRM1mediated nuclear export determines the cytoplasmic localization of the antiapoptotic protein survivin. Exp Cell Res 2002;275(1):44-53.

[45] Vegran F, Boidot R, Oudin C, et al. Distinct expression of survivin splice variants in breast carcinomas. Int J Oncol 2005;27(4):1151-7.

[46] Rohan TE, Li SQ, Hartwick R, et al. P53 alterations and protein accumulation in benign breast tissue and breast cancer risk: a cohort study. Cancer Epidemiol Biomarkers Prev 2006;15(7):1316-23.

[47] Sirotkovic-Skerlev M, Krizanac S, Kapitanovic S, et al. Expression of c-myc, erbB-2, p53 and nm23-H1 gene product in benign and malignant breast lesion: coexpression and correlation with clinicopathologic parameters. Exp Mol Pathol 2005;79(1):42-50. 